\title{
The Role of Social Influence in Anxiety and the Imposter Phenomenon
}

\author{
Christy B. Fraenza \\ Walden University
}

\begin{abstract}
High anxiety levels have been associated with high levels of the imposter phenomenon (IP), a negative experience of feeling like a fraud. This study was designed to explore IP among graduate students and to determine whether a difference exists between online graduate students and traditional graduate students. The theoretical foundation of this study was social influence, which holds that students may feel pressured in a traditional setting because of the social cues of peers and instructors, as well as institutional norms. This quantitative study used a between-subjects design to compare 2 independent samples (115 online students \& 105 traditional students). The study used a cross-sectional survey design, with 4 different measures: the Clance Imposter Phenomenon Scale, the Zung Self-Rating Anxiety Scale, the Perfectionistic Self-Presentation Scale, and a basic demographic survey. Results indicated that traditional graduate students had significantly higher IP scores than online graduate students. Results also indicated a significant, positive relationship between IP scores and anxiety scores. Regression analysis indicated that perfectionism was the most influential predictor of IP scores, followed by anxiety and program type. Because the scale used in this study explored socially prescribed perfectionism, the results appear to suggest an underlying social component to IP.
\end{abstract}

\section{Introduction}

The invention of the Internet has changed how individuals interact with one another on a daily basis. People use chatrooms, e-mails, and social networking websites instead of phone calls and lunch meetings to keep in touch. The advent of the Internet has also paved the way for online educational programs. Many of these programs utilize e-mail and asynchronous discussions to submit work and interact with peers and instructors. This type of interaction, typically referred to as computer-mediated communication (CMC), has changed the college classroom. In this setting, many of the social cues that may influence individuals are lost, such as body language. As outlined by Salter (2003), this type of 
interaction allows students to develop their own opinions over time rather than quickly responding to questions in a physical classroom. For those individuals who experience high levels of anxiety, the absence of these cues and pressures to respond may provide a level of comfort.

\section{Literature Review}

Individuals who experience the imposter phenomenon (IP) are stuck in a negative cycle of emotions. While they are typically very successful, they are unable to fully experience and own their achievements. They also may avoid extra academic pursuits, such as participating in conferences (Harvey, 1982). Regardless of success, these individuals believe they have somehow fooled everyone into believing they are more competent than they really are. These individuals live in a negative cycle of fear of discovery, over preparation, and experience high levels of anxiety (Kolligan \& Sternberg, 1991).

\section{The Imposter Phenomenon and Anxiety}

Researchers have indicated that IP is positively related to anxiety (Chae, Piedmont, \& Estadt, 1995). As discussed by Kolligan and Sternberg (1991), a key feature of IP is social anxiety, especially when there is imminent evaluation. The fear of discovery fuels anxiety levels, which may contribute to high levels of perfectionism as well as the imposter cycle. As outlined by Caselman et al., (2006), this cycle is characterized by a fear of failure that often leads to perfectionism and over preparation. This fear of discovery often pushes the individual to intensely focus on preparation in order to succeed at a task. However, this negative cycle of anxiety is often followed by success, which only reinforces the belief that their success was not legitimate (Caselman et al., 2006), and so the cycle continues.

\section{Graduate Students}

Researchers have explored IP in professions where anxiety is likely present, including family medicine residents (Oriel, Plane, \& Mundt, 2004), medical students (Henning, Ey, \& Shaw, 1998), physician assistants (Prata \& Gietzen, 2007), and marketing managers (Fried-Buchalter, 1992; 1997). Little research has explored IP in the population of graduate students, but it is commonly known that graduate school is full of anxiety-provoking assignments and experiences (Hadijoannou, Shelton, \& Dhanarattigannon, 2002). Horne (2011) qualitatively explored IP among a small sample of doctoral students and found that they commonly experienced anxiety and felt that they had been admitted into their programs by mistake.

Literature on IP is limited regarding graduate students, and no known studies have compared online graduate students to traditional graduate students. Previous studies on graduate students have indicated that online students experience lower levels of anxiety (DeVaney, 2010). Researchers have theorized that the loss of social cues and pressures in electronic communications may reduce anxiety associated with asking for help (Kitsantas \& Chow, 2007) and may create a more comfortable, open environment where all members are equal (Sullivan, 2002). Many cues about the context of an interaction are not present in electronic communication, such as body language, nonverbal cues, physical appearance, and emotional reactions (Parks \& Floyd, 1996). Without this information, communication online should result in less social influence and conformity in comparison to face-to-face communications (Parks \& Floyd, 1996). Because face-to-face communications are absent, or limited, in online graduate programs, it was theorized that online graduate students would experience less anxiety and less intense IP, when compared to their traditional counterparts.

\section{Social Influence}

The role of anxiety in IP was at the foundation of this study, as well as the potential impact of social influences. As discussed by Cialdini and Goldstein (2004), social influence refers to a change in behaviors or beliefs in response to experienced social forces. As discussed by Liao and Hsieh (2011), 
"another term for social influence is peer group pressure, or the pressure on a person to conform to a distinct group resulting in a specific behavior" (p. 888). Individuals in a traditional classroom setting may experience increased levels of social influence and pressure due to participation requirements within the classroom. Individuals with underlying anxiety may experience increased anxiety in this setting due to speaking in class and frequent interpersonal contact (Ioakimidis, 2010). However, this added pressure and anxiety may not be present in the online classroom as individuals are able to have more control over their communication with others (Okdie, Guadagno, Bernieri, Geers, \& Mclarney-Vesotski, 2011).

Social influences impact individuals every day during regular activities, including academic studies. Students are constantly confronted with social interactions when others around them attempt to change their attitudes, behavior, or beliefs (Mugny \& Guimond, 2007). Students experiencing high levels of anxiety may feel pressured in a traditional setting because of the perceived social cues of peers and instructors, as well as the pressures to conform to institutional norms. Such pressure in the social setting may limit a student's participation and learning and this added anxiety may be a contributing factor to the experience of IP. However, research has indicated that students feel more able to be themselves in an online classroom setting (Sullivan, 2002). Students have also stated that they felt the online classroom allowed everyone to be equal, as nobody knew what others looked like (Sullivan, 2002). Research has also indicated that students feel more comfortable asking for help through e-mail than in person (Kitsantas \& Chow, 2007). Researchers have theorized that this may be due to students' ability to construct a question and because online communication frees them from the nonverbal cues and social influence of the instructor and classmates (Kitsantas \& Chow, 2007). This research was designed to build on the body of literature about online learning and CMC by exploring anxiety levels and IP levels within this setting.

\section{Summary}

Individuals dealing with IP live their lives in constant fear of being discovered as less intelligent or competent than others believe them to be (Clance \& Imes, 1978). Even in the face of frequent success, this underlying fear of discovery pushes them to reach toward impossibly high standards of achievement and success. Instead of attributing their achievements to their abilities, they often attribute their success to luck, hard work, or the mistakes of others (Clance \& O’Toole, 1988). The negative cycle of IP leaves them in a state of uncomfortable anxiety, especially in the face of imminent evaluations (Kolligan \& Sternberg, 1991).

Frequent evaluations are a consistent thread across graduate programs; students are burdened by high workloads and deadlines. For an individual experiencing IP, a graduate school program is an anxiety-ridden chapter in their lives. It was theorized that individuals in online graduate programs may experience less underlying anxiety due to less social influence and interaction.

\section{Method}

\section{Procedures}

Written information introducing the study was posted to the participant pool service of a large online university. Enrolled online graduate students who had access to the participant pool were invited to participate. In addition, an announcement regarding the study was posted on the LinkedIn group page for the online university. Traditional graduate students were sent the same information via a listserv for the graduate student association at the large university. Graduate students that signed up for the listserv would receive announcements of interest to the graduate student population. But because the listserv is voluntary and not all graduate students would be on the list, it was decided to also contact each department head directly, who then forwarded information about the study to graduate students enrolled in their own departments. Students were invited to participate in the study by using the link within an e-mail that led 
them to the informed consent and questionnaires. After completing the surveys, participants were thanked for their participation and debriefed.

\section{Research Questions \& Hypotheses}

Research Question 1: Is there a significant difference in IP scores, as measured by the Clance Imposter Phenomenon Scale (CIPS), between online graduate students and traditional graduate students?

Null Hypothesis $\left(\mathrm{H}_{0} 1\right)$ : There will not be a statistically significant difference between the IP scores of online graduate students and traditional graduate students, as measured by the CIPS.

Alternate Hypothesis $\left(\mathrm{H}_{1} 1\right)$ : There will be a statistically significant difference in the IP scores, as measured by the CIPS, of online graduate students when compared to the IP scores of traditional graduate students. It is hypothesized that online graduate students will have lower IP scores than traditional graduate students.

Research Question 2: What is the nature of the relationship between IP, as measured by CIPS, and anxiety scores, as measured by the Zung Self-Rating Anxiety Scale (SAS)?

Null Hypothesis $\left(\mathrm{H}_{0} 2\right)$ : There will be no statistically significant relationship between IP, as measured by the CIPS, and anxiety, as measured by the SAS.

Alternate Hypothesis $\left(\mathrm{H}_{1} 2\right)$ : There will be a significant, positive relationship between IP, as measured by the CIPS, and anxiety, as measured by the SAS (Bernard, 2002; Chae et al., 1995).

Research Question 3: Is there a difference in anxiety scores, as measured by the SAS, between online graduate students and traditional graduate students?

Null Hypothesis $\left(\mathrm{H}_{0} 3\right)$ : There will not be a statistically significant difference between the anxiety scores, as measured by the SAS, of online graduate students and traditional graduate students.

Alternate Hypothesis $\left(\mathrm{H}_{1} 3\right)$ : There will be a statistically significant difference in the anxiety scores, as measured by the SAS, of online graduate students when compared to traditional graduate students. It is hypothesized that online graduate students will have significantly lower anxiety scores.

\section{Participants}

Participants were 220 graduate students from two different universities, with 105 enrolled in traditional programs and 115 enrolled in online programs. The sample was 76\% White and 16.4\% Black. Fifty-four participants were enrolled in a master's level program and 166 were pursuing a doctoral degree. Participants came from a variety of majors: $47.7 \%$ social science, $15 \%$ science, $5.9 \%$ business, $2.3 \%$ technology, $2.3 \%$ medicine, $8.2 \%$ education, $2.3 \%$ arts, and $16.4 \%$ other.

\section{Measures}

Demographics. A demographic questionnaire collected basic demographic information from each participant. Information included on this questionnaire consisted of: age, ethnicity, educational program, year in educational program, and previous graduate school experience.

Clance Imposter Phenomenon Scale (CIPS). The CIPS consists of 20 items that assess various aspects of IP, using a Likert-scale format (Clance, 1985). Participants rate their agreement or disagreement using a 5 -point scale $(1=$ not at all true, $2=$ rarely, $3=$ sometimes, $4=$ often, $5=$ very true $)$. Total scores can therefore range from 20 to 100, with higher scores corresponding to more severe IP. 
Holmes, Kertay, Adamson, Holland, and Clance (1993) found the CIPS had high internal consistency (coefficient alpha of .96). In comparison to the other used IP scale, the Harvey IP Scale, the CIPS has been shown to be a more reliable and sensitive instrument (Holmes et al., 1993).

Zung Self-Rating Anxiety Scale (SAS). The SAS is a 20-item questionnaire in which the participant is asked to indicate how often they have experienced certain symptoms associated with anxiety, using a Likert-scale format $(1=$ none OR a little of the time, $2=$ some of the time, $3=$ good part of the time, $4=$ most OR all of the time) (Zung, 1971). Participants report the frequency of symptoms over the previous week. The 20-items include both psychological symptoms, such as fear and nervousness, as well as physiological symptoms, such as sweating and insomnia (Bitsika, Sharpley, \& Bell, 2009). Total scores can range from 20 to 80, with a score above 36 indicating a level of anxiety that requires further assessment or treatment (Sharpley, Bitsika, \& Christie, 2010). De la Ossa, Martinez, Herazo, and Campo (2009), determined that the SAS had acceptable internal consistency with a coefficient alpha of .77. Sharpley and Rogers (1985) reported a coefficient alpha of .79.

Perfectionistic Self-Presentation Scale (PSPS). The PSPS was developed to assess an individual's level of focus on appearing perfect to other people, as well as an individual's level of avoidance regarding outward expressions of their flaws (Hewitt et al., 2003). The PSPS is a 27-item questionnaire, in which participants are asked to rate their level of agreement, using a Likert-scale format $(1$ = disagree strongly; 4 = neutral/undecided; and $7=$ strongly agree). The PSP includes three different dimensions of perfectionistic self-presentation, including nondisclosure of imperfection, nondisplay of imperfection, and perfectionistic self-presentation. Reynolds, Dowell, Peeters, Beene, Espino, and Longstreth (2007) described nondisclosure of imperfection as an individual's openness to reveal their own perceived flaws. Non-display of imperfection was described as an individual's focus on hiding any perceived imperfections and perfectionistic self-presentation was described as actively promoting one's self in order to have the appearance of being perfect (Reynolds et al., 2007). Three-week test-retest reliability values have indicated a high degree of consistency (perfectionistic self-promotion $=.83$; non-display of imperfection $=.84$; nondisclosure of imperfection $=.74$ ). Results have also suggested that these dimensions are linked with measures of social anxiety, in particular, the non-display of imperfection dimension (Hewitt et al., 2003). This measure was included to capture the impact of the social environment on the variables included within this study.

\section{Results}

\section{Research Question 1}

Research question 1 asked if there was a significant difference in IP scores, as measured by the Clance Imposter Phenomenon Scale (CIPS), between online graduate students and traditional students. In order to determine if there was a significant difference between online graduate students and traditional graduate students in IP scores, an independent $t$-test was used. Results of a Levene's Test for Equality of Variances indicated a sig value of .559, which indicated that the variances were equal. Results indicated a statistically significant difference between traditional graduate students and online graduate students on the CIPS, $t(193)=4.948, p<.001$. Traditional graduate students had a higher mean CIPS score of 65.68 $(S D=15.59)$ compared to the mean online graduate CIPS score of $54.17(S D=16.85)$. The effect size for this analysis $(d=.71)$ indicated a medium effect size. These results are provided in Table 1.

\section{Research Question 2}

Research question 2 asked what the nature of the relationship was between IP, as measured by CIPS, and anxiety scores, as measured by the SAS. A Pearson correlation was used to determine if there was a significant relationship between IP and anxiety. Results indicated that there was a significant, 
positive relationship between CIPS scores and SAS scores, $r(187)=.405, p<.001$. These results indicated a medium effect size.

\section{Research Question 3}

Research question 3 asked if there was a difference in anxiety scores, as measured by the SAS, between online graduate students and traditional graduate students. In order to determine if there was a significant difference between online graduate students and traditional graduates in anxiety scores, an independent $t$-test was used. The results of a Levene's Test for Equality of Variance indicated a sig value of .451, which indicated that the variances were equal. Traditional graduate students had higher anxiety scores $(M=37.49, S D=6.01)$ than online graduate students $(M=36.88, S D=6.76)$, however this difference was not significant, $t(211)=.693, p=.489$. The effect size for this analysis $(d=.10)$ indicated a small effect. These results are provided in Table 1.

Table 1

CIPS Scores and SAS Scores for Online and Traditional Graduate Students

\begin{tabular}{|c|c|c|c|c|}
\hline & \multicolumn{2}{|c|}{ Program Type } & \multirow[b]{2}{*}{$t$} & \multirow[b]{2}{*}{$d f$} \\
\hline & Online & Traditional & & \\
\hline CIPS Scores & $\begin{array}{l}54.17 \\
(16.85)\end{array}$ & $\begin{array}{l}65.68 \\
(15.59)\end{array}$ & $4.948 *$ & 193 \\
\hline SAS Scores & $\begin{array}{l}36.88 \\
(6.76)\end{array}$ & $\begin{array}{l}37.49 \\
(6.01)\end{array}$ & .693 & 211 \\
\hline
\end{tabular}

Note. ${ }^{*}=p \leq .001$. Standard deviation appears in parentheses below means.

\section{Additional Analysis}

Standard multiple linear regression was carried out to determine the effect of perfectionism, anxiety, and program type on IP scores. This was a statistically significant model, $F(3,172)=84.72, p<$ .001 , indicating these results were unlikely to have been obtained by chance. The adjusted $R^{2}$ indicated that $58.9 \%$ of the variance in IP scores can be explained by variances in the three predictor variables. The analysis suggested that perfectionism $(\beta=.638)$ was the most influential predictor, followed by anxiety $(\beta$ $=.192)$, and program type $(\beta=-.157)$. All three predictor variables were shown to be statistically significant predictors of IP score; these results are provided in Table 2.

Table 2

Regression Model with IP score as the Criterion Variable

\begin{tabular}{lllll}
\hline & $\begin{array}{l}\text { Unstandardized } \\
\text { Coefficients }\end{array}$ & $\begin{array}{l}\text { Standardized } \\
\text { Coefficients }\end{array}$ & $t$ & Sig. \\
\hline Constant & -.343 & & & \\
PSPS_Scores & .448 & .638 & 12.100 & .000 \\
SAS_Scores & .543 & .192 & 3.744 & .000 \\
Program Type & -5.403 & -.157 & -3.157 & .002 \\
\hline
\end{tabular}

Note: Adjusted $R^{2}=58.9 \% ; F(3,172)=84.72, p<.001$

\section{Discussion}

Results supported the hypothesis that online graduate students would show significantly lower IP scores than traditional graduate students, as well as the hypothesis that there would be a significant, positive relationship between IP scores and anxiety scores. Results indicated that traditional students had higher anxiety scores than online graduate students, however this result was not significant. Additionally, perfectionism was identified as the most influential predictor of IP scores. 
Results supported the premise that IP would be present within a sample of graduate students. Traditional graduate student participants had a mean score that indicated frequent imposter feelings $(M=$ 65.68, $S D=15.59$ ). Online graduate student participants had a mean score that indicated a moderate level of IP $(M=54.17, S D=16.85)$. Results also showed high levels of anxiety for both traditional graduate students $(M=37.49, S D=6.01)$ and online graduate students $(M=36.88, S D=6.76)$. A score of 36 or over on the SAS is considered high; in fact, it would suggest that an individual might need further assessment (Sharpley et al., 2010). Overall, these results indicate that graduate students, whether they are enrolled in online programs or traditional programs, are dealing with anxiety and IP.

Results indicated a significant, positive relationship between anxiety scores and IP scores. This finding supports previous research that IP and anxiety are positively related and adds to the body of literature that has explored this correlation (see Bernard, 2002; Chae et al., 1995; Ives, 2010). It also appears to further support the assumption that individuals in high-anxiety provoking professions or programs are likely to experience IP.

Although results indicated that traditional graduate students had significantly higher IP scores when compared to online graduate students, a significant difference in anxiety scores was not found. This finding seems to suggest that there must be another component involved in IP scores among graduate students. Following further analyses, perfectionism was found to be the most significant predictor of IP scores. The PSPS was used in order to assess the impact of the social environment on the variables within this study, as it was designed to explore a person's level of focus on appearing perfect to other people, as well as an individual's level of avoidance regarding outward expressions of their flaws (Hewitt et al., 2010). Socially prescribed perfectionism may be influential in interpersonal situations, because it has been shown to increase self-appraisal and attention, which in turn influences an individual's perceptions of their own abilities and behaviors (Aldan \& Bieling, 1993). As stated by Ives (2010), the IP experience is associated with worries about being discovered as a fraud, feelings of having tricked others, and a tendency to attribute success to outside influences. These factors of IP all seem to suggest an underlying social component to the IP experience; the individual with IP feels they have conned others about their abilities and are fearful of being discovered for doing so. Ultimately, perfectionism was found to be a powerful predictor of IP scores, even more so than type of program and anxiety, which seems to suggest that the social environment played a role in IP scores. As stated by Burnkrant and Cousineau (1975), one of the greatest influences on an individual's behavior is simply the influence of others around them. Because the scale used to assess perfectionism was only focused on socially prescribed perfectionism that is ultimately driven by social forces, it seems that an underlying social component could be a factor in the results. According to Hewitt (as cited by Benson, 2003), "interpersonal needs are what drive the perfectionistic behavior" (p. 3). These needs are the focus of the PSPS, which includes such items as "If I seem perfect, others will see me more positively" and "Errors are much worse if they are made in public rather than in private" (Hewitt et al., 2003, p. 1). However, it is also possible that personality characteristics not explored within this study played a role in these results. Researchers have explored personality characteristics related to IP and found positive correlations between neuroticism and IP (Bernard et al., 2002; Chae et al., 1995), however this was not explored in this study. As such, it is important to recognize that the results of this study do have limitations.

\section{Limitations of the Study}

One limitation of this study is the inability to infer any type of cause and effect relationship between the variables of interest. The design of the study only allowed for a numerical picture of the trends and relationships among the variables of interest. Because there was no intervention or manipulation of variables, it is beyond the scope of this study to determine if a particular learning environment caused certain levels of anxiety and IP. While significant differences were found between these groups on IP scores, it cannot be concluded that traditional graduate programs cause IP. 
Another concern is that the results are not generalizable to the greater graduate student population, as the sample utilized for this study was predominantly White. As described by the U.S. Department of Education, National Center for Education Statistics (2012), from 1976 to 2010, the percentage of White students fell from $83 \%$ to only $61 \%$, while the percentage of Black students rose from $9 \%$ to $14 \%$ and the percentage of Asian/Pacific Islander students rose from $2 \%$ to $6 \%$. Given this information regarding the larger graduate student population, the sample utilized for this study is not a true representation of the graduate student population.

Another limitation is that it is impossible to determine if the groups used in this study were equal on other variables not measured. For instance, one specific issue not addressed by this study was the timing of the questionnaires. Ioakimidis (2007) found that online students' computer anxiety tends to decrease over time, while the anxiety of traditional students remains steady. Because of the differences in the two different academic institutions within this study, it was not possible to ensure that the questionnaires were distributed at the same time of the academic quarter or semester. Therefore, this potential effect could not be explored.

Another factor not directly assessed in this study were differences in attrition between online graduate students and traditional graduate students. Patterson and McFadden (2009) found that students in an online Master's of Business Administration (MBA) program and a Master's in Communication Sciences and Disorders (MCSD) were more likely to drop out than students enrolled in the traditional version of these programs. It is unclear what the attrition rates are between online students and traditional students on a larger scale, but if there are differences, this is a limitation to this study. It is possible that online students could drop out at higher rates (possibly due to stress and anxiety) when compared to traditional students. If students who have experienced high levels of stress dropped out of their programs, they were not included within this study.

One last limitation related to the sample is that it was not random. Rather, the sample consisted of only graduate students who volunteered to complete the survey. It is very possible that those that volunteered to participate are somehow different from those that did not participate. For instance, those students who participated may have fewer responsibilities that allowed them the extra time to complete the surveys. Furthermore, researchers have noted that anxiety among imposters tends to increase during times of evaluation (Leary et al., 2000) and this could have also impacted participation. For instance, some students may have been completing final steps in their programs; this added anxiety related to evaluations could have kept from them participating.

\section{Future Directions}

This study has contributed to the overall literature on IP and has explored whether IP is experienced differently between learning environments. Because both traditional graduate students and online graduate students showed high levels of anxiety and IP, it is important to develop further research aimed at reducing these experiences within the population of graduate students. Ives (2010) investigated the impact of an orientation course on IP and anxiety among a sample of online graduate students and found that such a course could reduce the IP experience over time. However, this orientation course did not provide relief of anxiety (Ives, 2010). Further research into such interventions for both online graduate students and traditional graduate students is needed in order to reduce the negative experiences associated with IP and anxiety.

Furthermore, more research is needed to explore the relationship among social influence, anxiety, perfectionism, and IP. Future research could benefit from more in-depth assessments utilizing qualitative components in order to better understand the complex interactions among these variables. In addition, it is still unclear how the IP experience impacts academic performance. Future research could explore how the 
IP experience impacts the academic experience of graduate students and whether this experience is different between online and traditional educational settings.

\section{Conclusion}

This study contributes to the literature focused on IP by exploring differences between online graduate students and traditional graduate students. Online graduate students had lower IP scores when compared to traditional graduate students and socially prescribed perfectionism was identified as the strongest predictor of IP scores. Because socially prescribed perfectionism involves a social component, these results suggest that social influences may play a role in the IP experience.

\section{References}

Asch, S. E. (1956). Studies of independence and conformity: I. A minority of one against a unanimous majority. Psychological Monographs: General And Applied, 70(9), 1-70. doi:10.1037/h0093718

Alden, L.E., \& Bieling, P.M. (1993, August). Perfectionism in an interpersonal context. A paper presented at the Annual Meeting of the American Psychological Association, Ontario, Canada.

Austin, J., Cameron, T., Glass, M., Kosko, K., Marsh, F., Abdelmagid, R., \& Burge, P. (2009). First semester experiences of professionals transitioning to full-time doctoral study. The College Student Affairs Journal, 27(2), 194-214.

Bandura, A., Ross, D., \& Ross, S. A. (1963). A comparative test of the status envy, social power, and secondary reinforcement theories of identificatory learning. Journal of Abnormal \& Social Psychology, 67(6), 527-534.

Baralt, M., \& Gurzynski-Weiss, L. (2011). Comparing learners' state anxiety during task-based interaction in computer-mediated and face-to-face communication. Language Teaching Research, 15(2), 201-229. doi:10.1177/0265532210388717

Beck, A., Epstein, N., Brown, G., \& Steer, R. (1988). An inventory for measuring clinical anxiety: Psychometric properties. Journal of Consulting and Clinical Psychology, 56(6), 893-897. doi:10.1037/0022-006X.56.6.893

Benson, E. (2003). The many faces of perfectionism. Monitor, 34(10), 18. Retrieved from http://www.apa.org/monitor/nov03/manyfaces.aspx

Bernard, N.S., Dollinger, S.J., \& Ramaniah, N.V. (2002). Applying the big five personality factors to the imposter phenomenon. Journal of Personality $\quad$ Assessment, 78(2), 321-333.

Bitsika, V., Sharpley, C. F., \& Bell, R. (2009). The contribution of anxiety and depression to fatigue among a sample of Australian university students: Suggestions for university counsellors. Counselling Psychology Quarterly, 22(2), 243-255. doi:10.1080/09515070903216929

Burkholder, G. (n.d.). Study notes: Sample size analysis for quantitative studies. Research Methods. Los Angeles, CA: Laureate Education, Inc.

Burnkrant, R.E., \& Cousineau, A. (1975). Informational and normative social influence in buyer behavior. Journal of Consumer Research, 2(12), 206-215. 
Byrnes, K., \& Lester, D. (1995). The imposter phenomenon in teachers and accountants [Abstract]. Psychological Reports, 77(1), 350.

Caselman, T., Self, P., \& Self, A. (2006). Adolescent attributes contributing to the imposter phenomenon. Journal of Adolescence, 29(3), 395-405. doi:10.1016/j.adolescence.2005.07.003

Castro, D., Jones, R., \& Mirsalimi, H. (2004). Parentification and the impostor phenomenon: An empirical investigation. American Journal of Family Therapy, 32(3), $\quad$ 205-216. doi:10.1080/01926180490425676

Chae, J.H., Piedmont, R.L., Estadt, B.K., \& Wicks, R.J. (1995). Personological evaluation of Clance's Imposter Phenomenon Scale in a Korean sample. Journal of Personality Assessment, 65(3), 468-485.

Chrisman, S.M, Pieper, W.A., Clance, P.R., Holland, C.L., \& Glickauf-Hughes, C. (1995). Validation of the Clance Imposter Phenomenon Scale. Journal of Personality Assessment, 65(3), 456-467.

Cialdini, R. \& Goldstein, N. (2004). Social influence: Compliance and conformity. Annual Review of Psychology, 55, 591-621.

Cialdini, R.B., \& Trost, M.R. (1998). Social influence: Social norms, conformity, and compliance. In D.T. Gilbert, S.T. Fiske, \& G. Lindzey (Eds.), Handbook of social psychology, (4 ${ }^{\text {th }}$ ed., Vol. 2, pp. 151-193). New York, NY: McGraw Hill.

Cialdini, R.B., Vincent, J.E., Lewis, S.K., Catalan, J., Wheeler, D., \& Darby, B.L. (1975). Reciprocal concessions procedure for inducing compliance: The door-in-the-face technique. Journal of Personality and Social Psychology, 31(2), 206-215.

Claidière, N., \& Whiten, A. (2012). Integrating the study of conformity and culture in humans and nonhuman animals. Psychological Bulletin, 138(1), 126-145. doi:10.1037/a0025868

Clance, P.R. \& Imes, S.A. (1978). The imposter phenomenon in high achieving women: Dynamics and therapeutic intervention. Psychotherapy: Theory, Research and Practice, 15(3), 241-247.

Clance, P.R. (1985). The Imposter Phenomenon: When success makes you feel like a $\quad$ fake. $\quad$ New York, NY: Bantam Books.

Cohen, J. (1988). Statistical power analysis for the behavioral sciences ( $2^{\text {nd }}$ ed.). Hillsdale, NJ: Lawrence Erlbaum Associates.

Creswell, J. W. (2003). Research design: Qualitative, quantitative and mixed methods approaches (2nd ed.). Thousand Oaks, CA: Sage Publications, Inc.

Cromwell, B., Brown, N., Sanchez-Huceles, J., \& Adair, F. (1990). The imposter phenomenon and personality characteristics of high school honor students. Journal of Social Behavior and Personality, 5(6), 563-573.

de la Ossa, S., Martinez, Y., Herazo, E., \& Campo, A. (2009). Study of internal consistency and factor structure of three versions of the Zung's rating instrument for anxiety disorders. Colombia Médica, 40(1), 78-84. 
Deutsch, M., \& Gerard, H.B. (1955). A study of normative and informational social influences upon individual judgment. Journal of Abnormal and Social Psychology, 51, 629-636.

Dolinski, D. (2011). A rock or a hard place: The foot-in-the-face technique for inducing compliance without pressure. Journal of Applied Social Psychology, 41, 1514-1537.

Flett, G.L., Hewitt, P.L., Blankstein, K.R., \& Gray, L. (1998). Psychological distress and the frequency of perfectionistic thinking. Journal of Personality and Social Psychology, 75(5), 1363-1381.

Flett, G.L., Hewitt, P.L., Demerjian, A., Sturnam, E.D., Sherry, S.B., \& Cheng, W. (2011). Perfectionistic automatic thoughts and psychological distress in adolescents: An analysis of the perfectionism cognitions inventory. Journal of Rational-Emotive Cognitive-Behavior Therapy. doi: 10.1007/s10942-011-0131-7

Fogg, P. (2009). Grad-school blues. Chronicle of Higher Education, 55(24), 12-16.

Freedman, J. L., \& Fraser, S. C. (1966). Compliance without pressure: The foot-in-the-door technique. Journal of Personality \& Social Psychology, 4(2), 195-202.

Fried-Buchalter, S. (1997). Fear of success, fear of failure, and the imposter phenomenon among male and female marketing managers. Sex Roles, 37(11), 847-859. doi:10.1007/BF02936343

Gliem, J.A. \& Gliem, R.R. (2003). Calculating, interpreting, and reporting Cronbach's alpha reliability coefficient for Likert-type scales. 2003 Midwest Research to Practice Conference in Adult, Continuing, and Community Education. Retrieved from http://hdl.handle.net/1805/344

Goethals, G.R. (2003). A century of social psychology: Individuals, ideas, and investigations. In M.A. Hogg, \& J. Cooper (Eds.), The Sage handbook of social psychology (pp. 4-24). Thousand Oaks, CA: SAGE. Doi: 10.4135/978-1-84860-822-1.n1

Gravois, J. (2007). You're not fooling anyone. Chronicle of Higher Education, 54(11).

Green, K.E. (1997). Psychosocial factors affecting dissertation completion. New Directions for High Education, 99, 57-64.

Guéguen, N. (2003). Fund-raising on the web: The effect of an electronic door-in-the-face technique on compliance to a request. CyberPsychology \& Behavior, 6(2), 189-193.

Hadjioannou, X., Shelton, N., Fu, D., \& Dhanarattigannon, J. (2007). The road to a doctoral degree: Cotravelers through a perilous passage. College Student Journal, 41(1), 160-177.

Harvey, J.C. (1981). The imposter phenomenon and achievement: A failure to internalize success. Ph.D. dissertation, Temple University. Retrieved from Dissertations \& Theses: Full Text. (Publication No. AAT 8210500).

Harvey, J.C. \& Katz, C. (1985). If I'm so successful why do I feel like a fake? The imposter phenomenon. New York, NY: Simon and Shuster.

Heiman, G.W. (2003). Basic statistics for the behavioral sciences ( $4^{\text {th }}$ ed.). Boston, MA: Houghton Mifflin Co. 
Henning, K., Ey, S., \& Shaw, D. (1998). Perfectionism, the imposter phenomenon and psychological adjustment in medical, dental, nursing and pharmacy students. $\quad$ Medical Education, 32, 456464.

Hewitt, P.L., Flett, G.L., Sherry, S.B., Habke, M., Parkin, M., Lam, R.W., \& Stein, M.B. (2003). The interpersonal expression of perfection: Perfectionistic self-presentation and psychological distress. Journal of Personality and Social Psychology, 84, 1303-1325.

Holmes, S., Kertay, L., Adamson, L., \& Holland, C. (1993). Measuring the imposter phenomenon: A comparison of Clance's IP scale and Harvey's I-P scale. Journal of Personality Assessment, 60(1), 48-59. doi:10.1207/s15327752jpa6001_3

Humphris, G., \& Kaney, S. (1998). The encouragement of perfect health professionals. Medical Education, 32, 452-455.

Ioakimidis, M. (2007). Online or on campus: A student tertiary education cost model comparing the two, with a quality proviso. Higher Education in Europe, 32(2\&3), 249-260.

Ioakimidis, M. (2010). Home sweet home: Precluding two sources of academic stress in higher education through distance/e-learning. Georgian Electronic Scientific Journal: Education Science and Psychology, 2(17), 29-39.

Ives, S.K. (2010). The impact of an online orientation program on the imposter phenomenon, selfefficacy, and anxiety (Doctoral dissertation). Retrieved from ProQuest Digital Dissertations database. (AAT 3433523).

Kolligian, J., \& Sternberg, R. (1991). Perceived fraudulence in young adults: Is there an 'impostor syndrome'? Journal of Personality Assessment, 56(2), 308-326. doi:10.1207/s15327752jpa5602_10

Langford, J., \& Clance, P. (1993). The imposter phenomenon: Recent research findings regarding dynamics, personality and family patterns and their implications for treatment. Psychotherapy: Theory, Research, Practice, Training, 30(3), 495-501. doi: 10.1037/0033-3204.30.3.495

Marmor, J. (1998). Anxiety. The encyclopedia of mental health, 1, 212-216. Franklin $\quad$ Watts. doi: 10.1037/11558-011

Milgram, S. (1963). Behavioral study of obedience. Journal of Abnormal \& Social Psychology, 67(4), 371-378.

Milgram, S., Bickman, L., \& Berkowitz, L. (1969). Note on the drawing power of crowds on different size. Journal of Personality and Social Psychology, 13, 79-82.

McGregor, L., Gee, D., \& Posey, K. (2008). I feel like a fraud and it depresses me: The relation between the imposer phenomenon and depression. Social Behavior \& Personality: An International Journal, 36(1), 43-48.

Montgomery, R.L. (1992). Social influence and conformity: A transorientational model. In D. Gronberg \& G. Sarup (Eds.), Social Judgment and Intergroup Relations (pp. 175-200). New York, NY: Springer-Verlag. 
Moore, H.T. (1921). The comparative influence of majority and expert opinion. The American Journal of Psychology, 32(1), 16-20. Retrieved from http://www.jstor.org/stable/1413472

Nepon, T., Flett, G.L., Hewitt, P.L., \& Molnar, D.S. (2011). Perfectionism, negative social feedback, and interpersonal rumination in depression and social anxiety. Canadian Journal of Behavioral Science, 43(4), 297-308.

Nesdale, D., \& Pelyhe, H. (2009). Effects of experimentally induced peer-group rejection and out-group ethnicity on children's anxiety, self-esteem, and in-group and out-group attitudes. European Journal of Developmental Psychology, 6(2), 294-317. doi:10.1080/17405620601112436

Offstein, E.H., Larson, M.B., McNeill, A.L., \& Mwale, H.M. (2004). Are we doing enough for today's graduate student? The International Journal of Educational Management, 18(6/7), 396-407.

Parks, M.R., \& Floyd, K. (1996). Making friends in cyberspace. Journal of Communication, 46(1), 80-97.

Patterson, B., \& McFadden, C. (2009). Attrition in online and campus degree programs. Online Journal of Distance Learning Administration, 12(2). Retrieved from http://www.westga.edu/ distance/ojdla/summer122/patterson112.html

Penn State College of Agricultural Sciences. (2012). How to create a PSU Listserv. Retrieved from http://agsci.psu.edu/it/how-to/how-to-create-a-psu-listserv.

Price, V., Nir, L., \& Cappella, J. N. (2006). Normative and Informational Influences in Online Political Discussions. Communication Theory (10503293), 16(1), 47-74. doi:10.1111/j.14682885.2006.00005.X

Reynolds, W. M., Dowell, S. R., Peeters, L. A., Beene, K. E., Espino, A. E., \& Longstreth, D. (2007). Perfectionistic Self-Presentation Scale: Psychometric Characteristics in College Students. Washington, District of Columbia, US: American Psychological Association (APA).

Rhodewalt, F. (1990). Self-handicappers: Individual differences in the preference for anticipatory, self-protective acts. Self-handicapping: The paradox that isn't (pp. $\quad$ 69-106). New York, NY: Plenum Press.

Ross, S.R., Stewart, J., Mugge, M., \& Fultz B. (2001). The imposter phenomenon, achievement dispositions, and the five factor model. Personality and Individual Differences, 31, 13471355.

Sharpley, C.F., Bitsika, V., \& Christie, D.R.H. (2010). Why I feel bad: Refinement of the effects of prostate cancer upon lifestyle questionnaire and an initial exploration of its links with anxiety and depression among prostate cancer patients. Psycho-Oncology, 19, 839-846.

Schultz, P.W., Khazian, A.M., \& Zaleski, A.C. (2008). Using normative social influence to promote conservation among hotel guests. Social Influence, 3(1), 4-23. doi: 10.1080/15534510701755614

Snyder, T.D., \& Dillow, S.A. (2011). Digest of education statistics 2010. U.S. Department of Education. Retrieved from www.nces.ed.gov/pubs2011/2011015.pdf 
Sonnak, C. \& Towell, T. (2001). The imposter phenomenon in British university students: Relationships between self-esteem, mental health, parental rearing styles and socioeconomic status. Personality and Individual Differences, 31, 863-874.

Stein, E.L., \& Weidman, J.C. (1989, November). Socialization in graduate school: A conceptual framework. Paper presented at the Annual Meeting of the Association for the Study of Higher Education, Atlanta, GA.

Suler, J. (2004). The online disinhibition effect. CyberPsychology \& Behavior, 7(3), 321-326.

Thompson, T., Davis, H., \& Davidson, J. (1998). Attributional and affective responses of impostors to academic success and failure outcomes. Personality and Individual Differences, 25(2), 381396. doi:10.1016.S0191-8869(98)00065-8

Tolunay, A. (2005). Group identify effects on social influence (Doctoral dissertation). Retrieved from ProQuest Digital Dissertations database. (AAT 3186924).

Topping, M., \& Kimmel, E. (1985). The imposter phenomenon: Feeling phony [Abstract]. Academic Psychology Bulletin, 7(2), 213-226.

Triplett, N. (1898). The dynamogenic factors in pacemaking and competition. American Journal of Psychology, 9, 507-533. Retrieved from http://psychclassics.yorku.ca/Triplett/

U.S. Department of Education, National Center for Education Statistics. (2012). Digest of Education Statistics, 2011 (NCES 2012-001). Retrieved from http://nces.ed.gov/fastfacts/display.asp?id=98

Weisband, S.P., Schneider, S.K., \& Connolly, T. (1995). Computer-mediated communication and social information: Status salience and status differences. Academy of Management Journal, 38(4), $1124-1151$.

Wolniewicz, R. (1996, November). The psychology of the graduate student: A preliminary study. A paper presented at the Annual Meeting of the Speech Communication Association, San Diego, CA.

Zung, W.W.K. (1971). A rating instrument for anxiety. Psychosomatics, 12(6), 371-379 